\title{
Common N-acetylgalactosamine-6-sulfate sulfatase (GALNS) exon mutations in Brazilian patients with mucopolysaccharidosis IVA (MPS IVA)
}

\author{
Tatiana Dieter ${ }^{1}$, Ursula da Silveira Matte ${ }^{1,2}$, Ida Vanessa Schwartz ${ }^{3,4}$, Shunji Tomatsu ${ }^{5}$ \\ and Roberto Giugliani ${ }^{1,3,4}$ \\ ${ }^{1}$ Programa de Pós-Graduação em Ciências Médicas: Pediatria, \\ Universidade Federal do Rio Grande do Sul, Porto Alegre, RS, Brazil. \\ ${ }^{2}$ Centro de Terapia Gênica, Hospital de Clínicas de Porto Alegre, Porto Alegre, RS, Brazil. \\ ${ }^{3}$ Serviço de Genética Médica, Hospital de Clínicas de Porto Alegre, Porto Alegre, RS, Brazil. \\ ${ }^{4}$ Departamento de Genética, Universidade Federal do Rio Grande do Sul, Porto Alegre, RS, Brazil. \\ ${ }^{5}$ Department of Pediatrics, Pediatric Research Institute, Saint Louis University, Saint Louis, MO, USA.
}

\begin{abstract}
Morquio A Syndrome (mucopolysaccharidosis IVA - MPS IVA, OMIM\# 253000) is an autosomal recessive inborn error of metabolism caused by the deficiency of $\mathrm{N}$-acetylgalactosamine-6-sulfate sulfatase (GALNS). We investigated five unrelated Brazilian MPS IVA families for mutations in exons 4, 5, 9 and 10 of the GALNS gene. Six out of the 10 mutant alleles were identified. Taken together with a previous study, which included six unrelated families, common mutations among Brazilian patients were p.N164T, p.G116S and p.G301C. Among one hundred control subjects three novel silent mutations were found (p.A107A; GCC $\rightarrow$ GCT, p.Y108Y; TAC $\rightarrow$ TAT, p.P357P; CCG $\rightarrow$ CCA). Screening starting with exons 4, 5, 9, 10 and 11 may be a good strategy for genotyping of Brazilian patients since these exons include $73 \%$ of all mutations identified in the current and previous studies.
\end{abstract}

Key words: GALNS mutations, GALNS mutation detection, mucopolysaccharidosis IVA.

Received: July 10, 2006; Accepted: March 16, 2007.

Morquio A Syndrome (mucopolysaccharidosis IVA MPS IVA, OMIM\# 253000) is an autosomal recessive inborn error of metabolism of the lysosomal disorder group caused by the deficiency of N-acetylgalactosamine-6-sulfate sulfatase (GALNS: E.C.3.1.6.4) (Neufeld and Muenzer, 2001). MPS IVA is a rare disorder, incidence is estimated to be $1 / 216,000$ live births in British Columbia (Lowry et al., 1990); 1/76,000 live births in Northern Ireland based on notified cases over 30 years (Nelson et al., 1997); $1 / 450,000$ live births in the Netherlands over 26 years (Poorthuis et al., 1999); 1/201,000 in Australia (Meikle et al., 1999); 1/640,000 live births in Western Australia over 27 years (Nelson et al., 2003); and 1/450,000 live births in Portugal over 20 years (Pinto et al., 2004). GALNS is one of the sulfatases necessary for the degradation of keratan sulfate (KS) and condroitin-6-sulfate (CS). The restricted tissue distribution of KS leads to the unique clinical manifestations of this disorder (mainly skeletal al-

Send correspondence to Tatiana Dieter. Hospital de Clínicas de Porto Alegre, Centro de Pesquisas, Centro de Terapia Gênica, Rua Ramiro Barcelos 2350, Bairro Santa Cecília, 90035-903 Porto Alegre, RS, Brazil. E-mail: tatianadieter@gmail.com. terations). As in other mucopolysaccharidosis (MPS), MPS IVA shows a broad spectrum of clinical severity, presumably resulting from a wide variety of GALNS mutations. Clinical features include growth retardation, skeletal dysplasia, short trunk, dwarfism, odontoid hypoplasia and joint laxity (Northover et al., 1996 and Neufeld and Muenzer, 2001). Specific treatments (e.g. enzyme replacement and gene therapy) are under investigation.

The gene for GALNS is located on chromosome $16 \mathrm{q} 24.3$ and has 14 exons. The GALNS cDNA has an open reading frame of $1566 \mathrm{bp}$ which encodes a 522 amino acid protein. About 140 different mutations have been described, and approximately $70 \%$ of these are missense mutations (Tomatsu et al., 2005). Genotype/phenotype correlation exists for some of these mutations. Amino-acid changes or silent polymorphisms have also been described.

The aim of this study was to investigate mutations in the GALNS gene in Brazilian MPS IVA patients who were evaluated at the Medical Genetics Service (SGM), of the Hospital de Clínicas de Porto Alegre (HCPA, Porto Alegre, Rio Grande do Sul, Brasil) from 2004 to 2005. The MPS IVA diagnosis was confirmed by biochemical assay (van 
Diggelen et al., 1990), where the GALNS activity in leukocytes was less than $1 \%$ of normal controls and the arylsulfatase B activity (ARSB) was normal.

Between 2004 and 2005 our Genetics Service diagnosed six Brazilian MPS IVA patients (including two sibs), the clinical data for these patients being summarized in Table $1(\mathrm{n}=6$; patients 1-5) along with Genetics Service data for the seven Brazilian MPS IVA patients reported by Tomatsu et al. (2004a) (n =7; Patients 6-11). Written informed consent was obtained for each patient, and the study protocol was approved by the Institution Research Board at HCPA.

In our study, we screened GALNS gene exons 4, 5, 9 and 10 because our previous data showed that these were the most frequently mutated exons in Brazilian patients (Tomatsu et al., 2004a). The PCR and single-strand conformation polymorphism (SSCP) analysis conditions for these exons were standardized (Table 2). DNA was isolated from peripheral blood by the ammonium acetate method (Miller et al., 1988) and PCR was carried out with $100 \mathrm{ng}$ of genomic DNA in a total volume of $50 \mu \mathrm{L}$ on an Eppendorf Personal Thermal Cycler. The reaction include 1X PCR buffer, $0.2 \mathrm{mM}$ dNTPs, $1.5 \mathrm{mM}$ magnesium chloride $\left(\mathrm{MgCl}_{2}\right), 20 \mathrm{pmol}$ of each primer (forward and reverse) and $1 \mathrm{U}$ of Taq DNA polymerase (Invitrogen), dimethyl sulfo- xide (DMSO) being used only for exon 5 at a final concentration of $5.6 \%(\mathrm{w} / \mathrm{v})$. Primers were designed from the gene sequence and the PCR conditions were 5 min denaturation at $94{ }^{\circ} \mathrm{C}$, followed by 30 cycles of $30 \mathrm{~s}$ at $94{ }^{\circ} \mathrm{C}, 30 \mathrm{~s}$ at annealing temperature and $45 \mathrm{~s}$ at $72{ }^{\circ} \mathrm{C}$, followed by a final extension of $10 \mathrm{~min}$ at $72{ }^{\circ} \mathrm{C}$ (Table 2). To identify the GALNS exon alterations the PCR products (Figure 1) were submitted to SSCP analysis, performed with $8 \mu \mathrm{L}$ of PCR product and $4 \mu \mathrm{L}$ of SSCP buffer $(95 \%$ formamide, $20 \mathrm{mM}$ EDTA, $0.005 \%$ bromophenol blue, $0.05 \%$ xylene cyanol FF) which were mixed, heated to $95{ }^{\circ} \mathrm{C}$ for $5 \mathrm{~min}$ and chilled on ice before being loaded onto 8 or $12 \%(\mathrm{w} / \mathrm{v})$ non-denaturing polyacrylamide gel and subjected to electrophoresis using $1 \mathrm{X}$ TBE buffer. The SSCP conditions for exons 4, 5, 9 and 10 are given in Table 2. DNA bands on SSCP gels were visualized after silver nitrate staining (Orita et al., 1989). Fragments with an altered pattern were re-amplified, purified using the GFX PCR DNA and Gel Band Purification Kit (Amersham Biosciences) and sequenced on an ABI 310 sequencer (Applied - Byosystems) using the BigDye Terminator kit version 3.1.

Control PCR reactions, without DNA, were done in each reaction. The products from PCR reactions were checked on a $1.5 \%(\mathrm{w} / \mathrm{v})$ TBE-agarose gel containing ethidium bromide.

Table 1 - Clinical and genetic data for Brazilian patients with mucopolysaccharidosis (MPS) IVA. Patients 1 to 5 were analyzed by us for exons $4,5,9$ and 10 of the N-acetylgalactosamine-6-sulfate sulfatase (GALNS) gene exon. Patients 6 to 11 correspond to patients 17, 16, 18, 19,15 and 14 investigated by Tomatsu et al. (2004a) $)^{\dagger}$ and were analyzed regarding all the GALNS gene exons. Patients 3a and 3b, and 10a and 10b were sibs. The standard deviations (-SD) were as compared to age-matched normal controls (data from the National Center for Health Statistics at http://www.cdc.gov/nchs) and represent the number of standard deviations by which the patients are smaller or lighter than the controls, hence the negative values. A dash (-) indicates that data was not available, $\mathrm{ND}=$ not detected.

\begin{tabular}{|c|c|c|c|c|c|c|}
\hline $\begin{array}{l}\text { Patient and gender } \\
\mathrm{F}=\text { female, } \mathrm{M}=\text { male }\end{array}$ & $\begin{array}{c}\text { Consanguinity } \\
\text { and origin in } \\
\text { Brazil }\end{array}$ & $\begin{array}{c}\text { Age at onset of symptoms; age } \\
\text { at last evaluation }\end{array}$ & $\begin{array}{l}\text { Height } \\
(\mathrm{cm})\end{array}$ & $\begin{array}{l}\text { Weight } \\
(\mathrm{kg})\end{array}$ & $\begin{array}{l}\text { Walking } \\
\text { without } \\
\text { support }\end{array}$ & $\begin{array}{c}\text { GALNS genotype } \\
\text { *mutations exclusive } \\
\text { to Brazilian patients }\end{array}$ \\
\hline \multicolumn{7}{|l|}{ Present study } \\
\hline $1 \mathrm{M}$ & No, South & 12 months; 10 years 2 months & $105(-5.4 \mathrm{SD})$ & $28.1(-0.9 \mathrm{SD})$ & No & p.G301C / p.G301C \\
\hline $2 \mathrm{~F}$ & Yes, Southeast & $<6$ months; 9 years 10 months & 107 (-4.4SD) & $18.7(-2.6 \mathrm{SD})$ & Yes & ND \\
\hline 3a F (sib with 3b) & Yes, Northeast & 12 months; 6 years 5 months & $97.5(-3.8 \mathrm{SD})$ & $17.3(-1.4 \mathrm{SD})$ & Yes & ND \\
\hline 3b F (sib with 3a) & Yes, Northeast & 12 months; 7 years 7 months & 100 (-4.1SD) & $19.6(-1.4 \mathrm{SD})$ & Yes & ND \\
\hline $4 \mathrm{M}$ & No, Southeast & 48 months; 11 years & $103(-6.0 \mathrm{SD})$ & $20(-2.8 \mathrm{SD})$ & Yes & p.G301C / p.G301C \\
\hline $5 \mathrm{M}$ & Yes, South & 24 months; 22 years 1 month & - & $36(-1.7 \mathrm{SD})$ & No & p.N164T*/ p.N164T* \\
\hline \multicolumn{7}{|l|}{ Tomatsu et al., 2004a ${ }^{\dagger}$} \\
\hline $6 \mathrm{~F}$ & No, South & $<6$ months; - & - & - & - & p.G139S / p.N164T* \\
\hline $7 \mathrm{~F}$ & No, South & 36 months; 16 years 1 month & 104 (-8.7SD) & $22.5(-4.3 \mathrm{SD})$ & Yes & p.R386C / ND \\
\hline $8 \mathrm{M}$ & Yes, South & 24 months; 11 years 5 months & $113(-4.7 \mathrm{SD})$ & $28.5(-1.5 \mathrm{SD})$ & No & p.N164T*/p.N164T* \\
\hline $9 \mathrm{M}$ & No, South & 36 months; 15 years 6 months & 103 (-8.9SD) & $22.0(-4.0 \mathrm{SD})$ & Yes & p.G116S / p.G116S \\
\hline 10a M (sib with 10b) & No, Northeast & - ; 2 years & $82.5(-1.0 \mathrm{SD})$ & $11.0(-1.3 \mathrm{SD})$ & Yes & p.L307P*/p.S341R* \\
\hline 10b M (sib with 10a) & No, Northeast & 18 months; 6 years & 97 (-3.9SD) & $15.0(-2.3 \mathrm{SD})$ & Yes & p.L307P*/p.S341R* \\
\hline $11 \mathrm{M}$ & Yes, South & 12 months; 7 years 8 months & 99.5 (-4.9SD) & $21.0(-1.2 \mathrm{SD})$ & Yes & p.G116S / p.G116S \\
\hline
\end{tabular}

${ }^{\dagger}$ Tomatsu S, Dieter T, Schwartz IV, Sarmient P, Giugliani R, Barrera LA, Guelbert N, Kremer R, Repetto GM, Gutierrez MA, Nishioka T, Serrato OP, Montano AM, Yamaguchi S and Noguchi A (2004a) Identification of a common mutation in mucopolysaccharidosis IVA: Correlation among genotype, phenotype, and keratan sulfate. J Hum Genet 49:490-494. 
Table 2 - Polymerase chain reaction (PCR) and single-strand conformation polymorphism (SSCP) analysis conditions.

\begin{tabular}{|c|c|c|c|c|c|c|c|}
\hline Exon & Primers $\mathrm{F}=$ forward, $\mathrm{R}=$ reverse & $\begin{array}{l}\text { Annealing tem- } \\
\text { perature }\left({ }^{\circ} \mathrm{C}\right)\end{array}$ & $\begin{array}{l}\text { Fragment } \\
\text { size (bp) }\end{array}$ & $\begin{array}{l}\text { Polyacrylamide gel } \\
\text { concentration }(\% \mathrm{w} / \mathrm{v})\end{array}$ & $\begin{array}{l}\text { Voltage } \\
\text { (V) }\end{array}$ & $\begin{array}{l}\text { Running } \\
\text { time (h) }\end{array}$ & $\begin{array}{c}\text { Temperature } \\
\left({ }^{\circ} \mathrm{C}\right)\end{array}$ \\
\hline 4 & $\begin{array}{l}\text { F: GCTTCTCGGGGTCTCCTCG } \\
\text { R: GTGGATGGAGCAGGACGCC }\end{array}$ & 61 & 193 & 12 & 230 & 2 & $18-24$ \\
\hline 5 & $\begin{array}{l}\text { F: GTGGGGTCCCTGAAGTGTC } \\
\text { R: CGTGGGAGGGGAAGGGG }\end{array}$ & 60 & 212 & 12 & 200 & 3.5 & 4 \\
\hline 9 & $\begin{array}{l}\text { F: CTGGTCCCAGTGGCCTGAC } \\
\text { R: CTGCTGCCCGGCAGACCG }\end{array}$ & 61 & 176 & 12 & 50 & 15 & 4 \\
\hline 10 & $\begin{array}{l}\text { F: CAGAGTGCCCTGACCGTG } \\
\text { R: CTCTGGGCTTCACTACTTG }\end{array}$ & 57 & 231 & 8 & 250 & 2 & $18-24$ \\
\hline
\end{tabular}

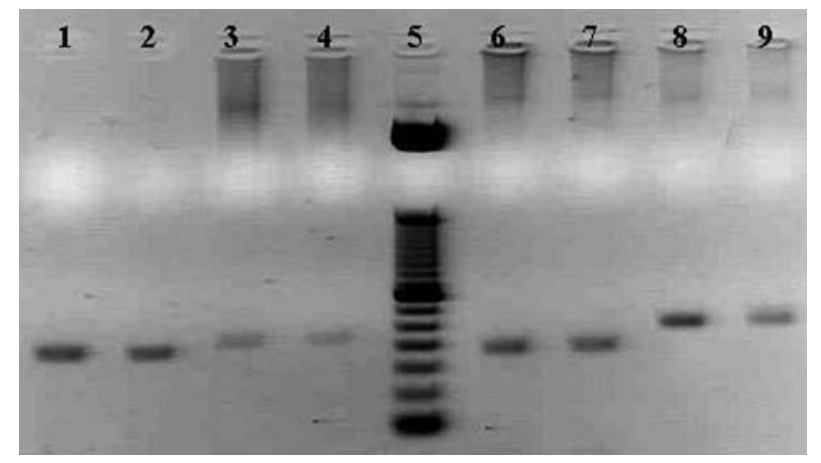

Figure 1 - PCR products on $1.5 \%(\mathrm{w} / \mathrm{v})$ TBE-agarose gel: lanes 1 and 2, exon 4; lanes 3 and 4, exon 5; lane 5,50 pb DNA ladder; lanes 6 and 7, exon 9; and lanes 8 and 9, exon 10.

We used SSCP analysis to screen 100 Brazilian control individuals (anonymous blood donors from Southern Brazil) in the same way as the patients. Analysis of 200 chromosomes in the general population is a methodology used for assessing the frequency of disease-causing recessive variants (Cotton and Scriver, 1998).

Missense mutations in the GALNS gene (p.N164T and p.G301C) were detected in three of the five unrelated patients studied (Patients 1 to 5 in Table 1). These mutations were not detected in the control sample of 100 subjects.

Molecular analyses for MPS IVA have been performed previously in various ethnic populations. However, with the exception of our previous study (Tomatsu et al., 2004a), there are no other data on Brazilians patients. The two missense mutations (p.N164T and p.G301C) that we found in the present study account for $\sim 70 \%$ of the mutant alleles so far investigated in Brazilian patients.

We estimated the frequency of the different mutations detected in 11 unrelated patients from our Genetics Service, i.e. the five described for the first time in our present paper and the six reported by Tomatsu et al. (2004a). We detected 17 out of the 22 mutated alleles (77.3\%), but three homozygous patients were from consanguineous marriages so we corrected these values by one allele per consanguineous marriage and estimated the relative frequency of the detected mutations among 14 mutated alleles (Table 3).
Table 3 - Type and frequency of N-acetylgalactosamine-6-sulfate sulfatase (GALNS) mutations in Brazilian patients with mucopolysaccharidosis IVA (MPS IVA), all presenting with a severe phenotype. The mutations were detected in the present study and by Tomatsu et al. $(2004 \mathrm{a})^{\dagger}$. Of the 17 mutations identified in unrelated patients, Only 14 alleles were used because in three homozygous individuals the alleles were identical by descent (consanguineous parents).

\begin{tabular}{llccc}
\hline $\begin{array}{l}\text { Nucleotide } \\
\text { change** }\end{array}$ & Codon alteration & Exon & $\begin{array}{c}\text { Amino-acid } \\
\text { change }\end{array}$ & $\begin{array}{c}\text { Frequency (\%) } \\
\mathrm{N}=14 \text { alleles* }\end{array}$ \\
\hline $445 \mathrm{G} \rightarrow \mathrm{A}$ & $\mathrm{GGC} \rightarrow \mathrm{AGC}$ & 4 & p.G116S & 17.6 \\
$514 \mathrm{G} \rightarrow \mathrm{A}$ & $\mathrm{GGC} \rightarrow \mathrm{AGC}$ & 4 & p.G139S & 5.9 \\
$590 \mathrm{~A} \rightarrow \mathrm{C}$ & $\mathrm{AAC} \rightarrow \mathrm{ACC}$ & 5 & p.N164T & 17.6 \\
$1000 \mathrm{G} \rightarrow \mathrm{T}$ & $\mathrm{GGC} \rightarrow \mathrm{TGC}$ & 9 & p.G301C & 23.5 \\
$1019 \mathrm{~T} \rightarrow \mathrm{C}$ & $\mathrm{CTG} \rightarrow \mathrm{CCG}$ & 9 & p.L307P & 5.9 \\
$1122 \mathrm{C} \rightarrow \mathrm{A}$ & $\mathrm{AGC} \rightarrow \mathrm{AGA}$ & 10 & p.S341R & 5.9 \\
$1255 \mathrm{C} \rightarrow \mathrm{T}$ & $\mathrm{CGT} \rightarrow \mathrm{TGT}$ & 11 & p.R386C & 5.9 \\
\hline
\end{tabular}

**GenBank entry: NM 000512.3..'Tomatsu S, Dieter T, Schwartz IV, Sarmient P, Giugliani R, Barrera LA, Guelbert N, Kremer R, Repetto GM, Gutierrez MA, Nishioka T, Serrato OP, Montano AM, Yamaguchi S and Noguchi A (2004a) Identification of a common mutation in mucopolysaccharidosis IVA: correlation among genotype, phenotype, and keratan sulfate. J Hum Genet 49:490-494.

Up to now, 12 different missense mutations have been found in Brazilian patients (Tomatsu et al., 2005) and, indeed, four of these mutations (p.G116S, p.N164T, p.L307P, p.S341R) were first described in Brazilian patients and, except for p.G116S which has also been found in a non-Brazilian patient, may be confined to the Brazilian population (Tomatsu et al., 2004a and 2005). The frequency of mutations in exons 4, 5, 9 and 10 in Brazilian patients (around $70 \%$ of mutant alleles) is higher than the $40 \%$ in the compiled data (Tomatsu et al., 2005). In our previous study we confirmed the allelic heterogeneity observed in this disorder where $46.1 \%$ of the mutations reported were private or occurred at a low frequency (Tomatsu et al., 2004a and Tomatsu et al., 2005).

The p.G116S, p.N164T, and p.G301C mutations could be explained as either "true recurrent mutations" or "common founder mutations" since they were observed among unrelated Brazilian patients. The other two common mutations, p.G139S and p.R386C, are considered as "true 
recurrent mutations" since they have been found in other ethnic populations (Tomatsu et al., 2005). Haplotype analysis is needed to confirm these data.

In a recent study on the mutation spectrum of the GALNS gene, it was shown that the three most frequent mutations, p.R386C, p.G301C and p.I113F account for only $20 \%$ of the identified mutant alleles (Tomatsu et al., 2005). These data suggest that genotyping for MPS IVA patients should be done for each ethnic population since it seems that the majority of mutations are sporadic or unique to each ethnic group.

The frequency of $\mathrm{p} \cdot \mathrm{R} 386 \mathrm{C}$, the most common mutation in most populations studied, may have been underestimated in our study because the new patients were not analyzed for exon 11 where this mutation is present. Among six Brazilian patients who had this exon analyzed this mutation was found only in one allele (Tomatsu et al., 2004a). Further studies are needed to clarify the situation regarding this mutation. The p.G301C mutation was very common in Colombian MPS IVA patients where it accounted for $70 \%$ of the mutant alleles investigated, and it was found also in Italian, French, British, Portuguese, and Moroccan patients (Tomatsu et al., 2005), while the p.G139S was described in $1.3 \%$ of the alleles of Irish, Argentine and North American patients from the USA (Tomatsu et al., 2004a).

None of the mutations observed in our Brazilian patients (p.G116S, p.N164T, p.L307P and p.S341R) were found in our control group of 100 individuals. There were 16 nonpathogenic variants of the GALNS gene with a single nucleotide change in the data compiled by Tomatsu et al. (2005). In the control group of this study, three novel silent nucleotide changes were found, p.A107A (GCC $\rightarrow$ GCT), p.Y108Y (TAC $\rightarrow$ TAT), p.P357P (CCG $\rightarrow$ CCA), but none of the previously reported silent mutations.

Analyzing the number of all the described mutations in the GALNS exons and the expected number of mutations based on exon size, we observed that mutations are not randomly distributed along the gene $(\mathrm{p}<0.01)$. Our data predict that exons 5, 10 and 11 are hot spots for mutations because they were present at frequencies above the expected frequencies, this increase being $83 \%$ for exon 5 , $42 \%$ for exon 10 and $56 \%$ for exon 11 . Mutations in exons $4,5,9$ and 10 accounted for almost $40 \%$ of all mutations so far identified. In Brazilian patients, the mutation frequency in these four exons was higher, as 13 out of 14 presumably independently mutated alleles $(92.9 \%)$ are located in these two exons, as detected by the present study and by Tomatsu et al., (2004a) (Table 3). These data suggest that for Brazilian patients it may be a good strategy to start analyzing exons 4, 5, 9 and 10. Moreover, exon 11 should also be analyzed since it posses the more frequent mutation (p.R386C) in other populations.

In respect to phenotype, $68.2 \%$ of all the complied mutations are associated with the severe phenotype, $21 \%$ with the attenuated phenotype and $10.8 \%$ have not been defined (Terzioglu et al., 2002; Tomatsu et al., 2005). In our patients, onset of signs and symptoms occurred around 20 months of age ( $\mathrm{SD} \pm 13.4$ months), in accordance with the literature that reports an onset age of around two years of age and final diagnosis at about three years of age (Northover et al., 1996). The standard deviations (-SD) shown in Table 1 were as compared to age-matched normal controls (data from the National Center for Health Statistics) and represent the number of standard deviations by which the patients are smaller or lighter than the controls, hence the negative values. The age of the Brazilian patients at examination ranged from 2 years to 21 years and 3 months and, compared with data from the age-matched normal controls from the National Center for Health Statistics, height was in the range $82.5 \mathrm{~cm}$ to about $113 \mathrm{~cm}$ (-1 to about -8.9 standard deviations (SD), i.e. less than the controls) and weight was 11 to about $36 \mathrm{~kg}(-0.9$ to about $-4.3 \mathrm{SD}$, i.e. less than the controls). Since all the patients, except patient 10a, had stopped, or nearly stopped, growing, they all presented a severe phenotype with a final height under $125 \mathrm{~cm}$ and, accordingly, all the mutations listed here were associated with the severe phenotype.

In this study, PCR and SSCP conditions were established for exons 4, 5, 9 and 10 of GALNS gene where the majority of mutations were reported for Brazilian MPS IVA patients. Using this strategy, we detected six out of 10 mutated alleles in five patients with Morquio A Syndrome. Common mutations among Brazilian patients are p.N164T, p.G116S, and p.G301C.

\section{Acknowledgments}

We thank Brazilian agencies CNPq and FIPE/HCPA for support.

\section{References}

Cotton RG and Scriver CR (1998) Proof of "disease causing" mutation. Hum Mutat 12:1-3.

Lowry RB, Applegarth DA, Toone JR, MacDonald E and Thunem NY (1990) An update on the frequency of mucopolysaccharide syndromes in British Columbia. Hum Genet 85:389-390.

Meikle PJ, Hopwood JJ, Clague AE and Carey WF (1999) Prevalence of lysosomal storage disorders. JAMA 281:249-254.

Miller SA, Dykes DD and Polesky HF (1988) A simple salting out procedure for extracting DNA from human nucleated cells. Nucleic Acids Res 16:1215.

Nelson J (1997) Incidence of the mucopolysaccharidosis in Northern Ireland. Hum Genet 101:355-358.

Nelson J, Crowhurst J, Carey B and Greed L (2003) Incidence of the mucopolysaccharidosis in Western Australia. Am J Med Genet 123:310-313.

Neufeld EF and Muenzer J (2001) The mucopolysaccharidoses. In: Scriver CR, Beaudet AL, Sly WS and Valle D (eds) The Metabolic and Molecular Basis of Inherited Disease. McGraw-Hill, New York, pp 3421-3452. 
Northover H, Cowie RA and Wraith JE (1996) Mucopolysaccharidosis type IVA (Morquio syndrome): A clinical review. J Inherit Metab Dis 19:357-365.

Ogawa T, Tomatsu S, Fukuda S, Yamagishi A, Rezvi GM, Sukegawa K, Kondo N, Suzuki Y, Shimozawa N and Oru T (1995) Mucopolysaccharidosis IVA: Screening and identification of mutations of the N-acetylgalactosamine-6-sulfate sulfatase gene. Hum Mol Genet 4:341-349.

Orita M, Suzuki Y, Sekiya T and Hayashi K (1989) Rapid and sensitive detection of point mutations and DNA polymorphisms using the polymerase chain reaction. Genomics 5:874-879.

Pinto R, Caseiro C, Lemos M, Lopes L, Fontes A, Ribeiro H, Pinto E, Silva E, Rocha S, Marcao A, et al. (2004) Prevalence of lysosomal storage diseases in Portugal. Eur J Hum Genet 12:87-92.

Poorthuis BJ, Wevers RA, Kleijer WJ, Groener JE, de Jong JG, van Weely S, Niezen-Koning KE and van Diggelen OP (1999) The frequency of lysosomal storage diseases in The Netherlands. Hum Genet 105:151-156.

Saínz CM, Muñoz CZ and Monteagudo AG-Q (2002) Errores innatos del metabolismo. Enfermedades lisosomales / metabolism inborn errors. Lysosomal storage diseases. Rev Cuba Pediatr 74:68-76.

Terzioglu M, Tokatli A, Coskun T and Emre S (2002) Molecular analysis of Turkish mucopolysaccharidosis IVA (Morquio A) patients: Identification of novel mutations in the
$\mathrm{N}$-acetylgalactosamine-6-sulfate sulfatase (GALNS) gene. Hum Mutat 20:477-478.

Tomatsu S, Dieter T, Schwartz IV, Sarmient P, Giugliani R, Barrera LA, Guelbert N, Kremer R, Repetto GM, Gutierrez MA, et al. (2004a) Identification of a common mutation in mucopolysaccharidosis IVA: Correlation among genotype, phenotype, and keratan sulfate. J Hum Genet 49:490-494.

Tomatsu S, Filocamo M, Orii KO, Sly WS, Gutierrez MA, Nishioka T, Serrato OP, Di Natale P, Montano AM, Yamaguchi S et al. (2004b) Mucopolysaccharidosis IVA (Morquio A): Identification of novel common mutations in the $\mathrm{N}$-acetylgalactosamine-6-sulfate sulfatase (GALNS) gene in It alian patients. Hum Mutat 24:187-188.

Tomatsu S, Montano AM, Nishioka T, Gutierrez MA, Pena OM, Tranda Firescu GG, Lopez P, Yamaguchi S, Noguchi A and Orii T (2005) Mutation and polymorphism spectrum of the GALNS gene in mucopolysaccharidosis IVA (Morquio A). Hum Mutat 26:500-512.

van Diggelen OP, Zhao H, Kleijer WJ, Janse HC, Poorthuis BJ, van Pelt J, Kamerling JP and Galjaard H (1990) A fluorimetric enzyme assay for the diagnosis of Morquio disease type A (MPS IV A). Clin Chim Acta 187:131-139.

\section{Internet Resource}

National Center for Health Statistics, http://www.cdc.gov/nchs. Associate Editor: Peter L. Pearson 